\title{
Carnitine Content of Blood and Amniotic Fluid
}

\author{
P. HAHN, ${ }^{(16)}$ J. P. SKALA, D. W. SECCOMBE, J. FROHLICH, D. PENN-WALKER, M. NOVAK, \\ I. HYNIE, AND M. E. TOWELL

\begin{abstract}
Deparment of Pediatrics, University of Miami, Miami, W. Beaumont Hospital, Royal Oak, Michigan, USA; and Bureau of Human Ecology, Health and Wolfare, Ottawa, Department of P'aediatrics and Department of Obstetrics and Gynaecology, University of British Columbia, British Columbia, Canada
\end{abstract}

\begin{abstract}
Summary
Free carnitine levels were determined in amniotic fluids between the 10th and 40th week of gestation. They were found to decrease significantly with gestational age. Blood levels of carnitine were lower in pregnant than in nonpregnant women. Levels were found to be higher in cord blood than in maternal blood and usually were higher in the umbilical artery than vein. Intraarterial injection of $\mathrm{L}$-carnitine into a pregnant ewe did not cause a rise in the fetal blood level of carnitine, which, in contrast to human fetal blood, contained less than half the level of carnitine in maternal blood.
\end{abstract}

\section{Speculation}

It is suggested that the placenta may play a role in carnitine transport from mother to fetus and that fetal blood and amniotic fluid levels may reflect retention of carnitine by fetal tissues.

L-carnitine (trimethylaminohydroxybutyric acid) is necessary for optimal transfer of acyl groups across mitochondrial membranes and thus for mitochondrial fatty acid oxidation (5). Several enzymes, collectively called carnitine acyltransferases, are responsible for the reaction

$$
\text { Acyl-CoA + carnitine }=\text { acylärnitine }+\operatorname{CoA}
$$

Since in most mammals, including man, the rate of fatty acid oxidation is low in fetuses and increases rapidly after birth, as evidenced, for example, by the low rate of ketone production by fetal rat liver in comparison to liver from newborn animals (4, $10)$, it would appear that the need for carnitine and the transferases should be higher post- than prenatally. This has been shown to be the case in the rat where carnitine content and carnitine acyltransferase activities increase soon after birth in liver (1), heart, brown fat, and even brain (7). In fact, it has been suggested that the tissue which utilizes the largest amounts of FA also contains the largest amount of carnitine and the highest transferase activity (8). We have shown that, in contrast to the rat, human (6) and monkey (9) fetal tissues show relatively high transferase activities. In addition, injection of $\left[{ }^{1+} \mathrm{C}\right]$ carnitine into pregnant rats results in the appearance of the label in amniotic fluid (11).

In view of the above, we considered it of interest to examine the carnitine content of human amniotic fluid and umbilical and maternal blood.

\section{MATERIALS AND METHODS}

Amniotic fluid (AF) was obtained from fetuses aged 9-40 weeks, either during delivery or by amniocentesis or during legal abortions. Umbilical blood and maternal venous blood were collected at the time of delivery.

Carnitine in AF was usually determined without prior deproteinization. Blood serum was deproteinized with either per- chloric acid or barium hydroxide and zinc sulfate. After neutralization and centrifugation, the supernatant was assayed for carnitine.

Carnitine was determined by an automated method developed by us (12). Sometimes the radioactive method of Cederblad and Lindstedt (2) was used, particularly for $A F$, where levels were low. No attempt was made to determine acetyl and acylcarnitine in our samples. However, further work has shown that these form only a fraction of the free carnitine, particularly in AF (unpublished data).

An attempt was also made to assess the transport of carnitine across the ovine placenta. A pregnant ewe (130)th day of pregnancy, 130 pounds body weight) was injected intra-arterially (carotid) with a bolus of L-carnitine in saline neutralized to $\mathrm{pH}$ $7.1(1 \mathrm{ml}$ containing 5() $\mathrm{mg})$ and samples of maternal and fetal blood were taken at the intervals shown in Figure 6. The fetus had been chronically catheterized 1 week before the experiment (for details see Reference 14).

\section{RESULTS}

\section{AMNIOTIC FLUID}

Free carnitine content of amniotic fluid decreases with gestational age, the correlation coefficient for concentration algainst gestational age being $r=0.0776, P<0.001$ (Fig. I). In fluids from infants of diabetic mothers (IDM) levels of free carnitine appeared to be lower. In a further series of 17 IDM and 12 control fluids, this did not seem to be true since the level in IDM fluids was $7.17 \pm 0.6$ against a control value of $7.5 \pm 0.7 \mathrm{nmol} /$ ml. However, this was due to the age spread of the IDM group. On week 38 of gestation, there is a highly significant difference between control values $(10.9 \pm 1.0)$ and levels in IDM $(5.5 \pm$ $0.88, P<0.0(01)$. It was also found that in the IDM group there was, just as in the control group, a highly significant $(P<0.001)$ negative correlation between gestational age and amniotic fluid carnitine content (Fig. 2). Maternal blood levels at the time of delivery were low, much lower than in nompregnant women $(17.1 \pm 3 \mathrm{nmol} / \mathrm{ml}$ for pregnant women against $46 \pm 3.2$ for nonpregnant ones, $P<0 .(001)$.

\section{FETAL AND NEONATAL BLOOD}

The carnitine content of mixed umbilical blood was around 20 $\mu \mathrm{M}$ and remained unchanged during the first 3-6 days of life. Arterial umbilical blood levels were found to be usually higher than venous levels (Fig. 3) and both arterial and mixed umbilical blood contained more carnitine than maternal venous blood (Fig. 4). No relationship between blood levels of carnitine and body weight at birth was found (Fig. 5).

\section{TRANSFER OF: CARNITINE IN PREGNANT EWE}

Figure 6 shows that, in contrast to man, the level of carnitine in ovine fetal blood is considerably lower than in the pregnant 
ewe. The rapid intravenous injection of L-carnitine into the mother led to a transient rise in camitine content in maternal blood but had no effect on the low fetal blood level.

\section{DISCUSSION}

Carnitine can be produced by lysine in the liver (3). It is zonsumed as such in meat and also in milk. How far the fetus can

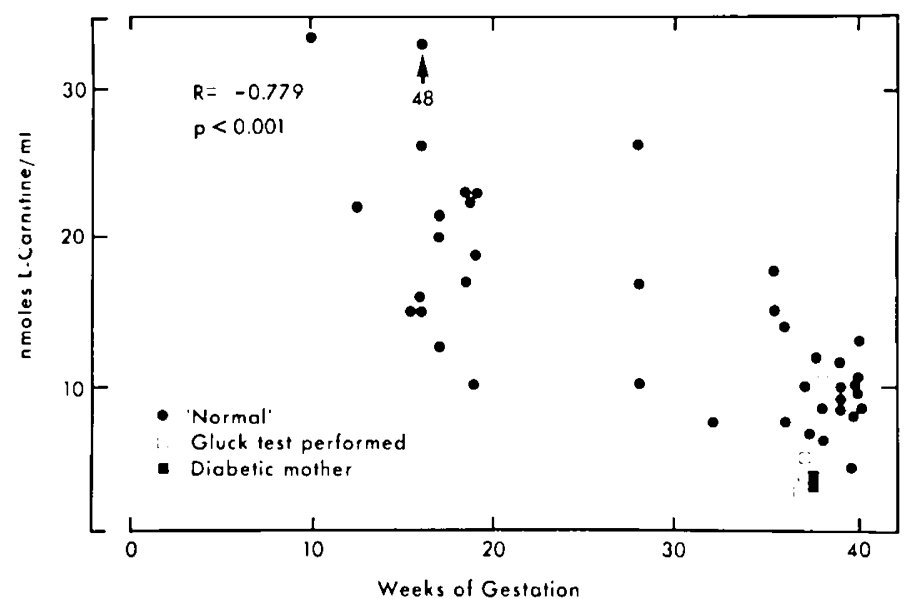

Fig. 1. Levels of free carnitine in amniotic fluid of human fetuses alged $10-40$ weeks. Gluck test performed indicates that prematurity and/or lung immaturity were suspected.

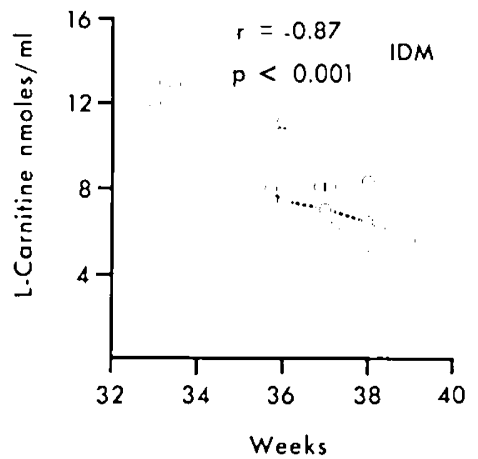

Fig. 2. Relationship belween gestational age and L-carnitine content of amniotic fluid in infants of diabetic mothers. The four points joined by the interrupted line are from the same patient.

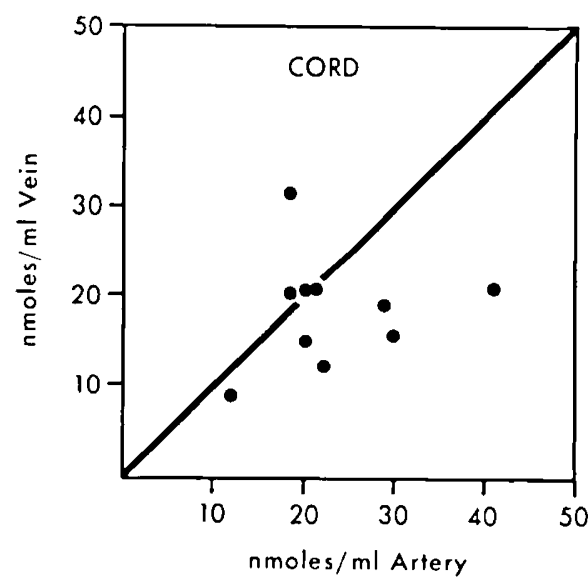

Fig. 3. Relationship between 1 -carnitine kevels in umbilical blood and vein. Note that in only 1 case was the level higher in the vein than in the artery, whereas in 6 out of 10 cases, it wals higher in the artery than in the vein.

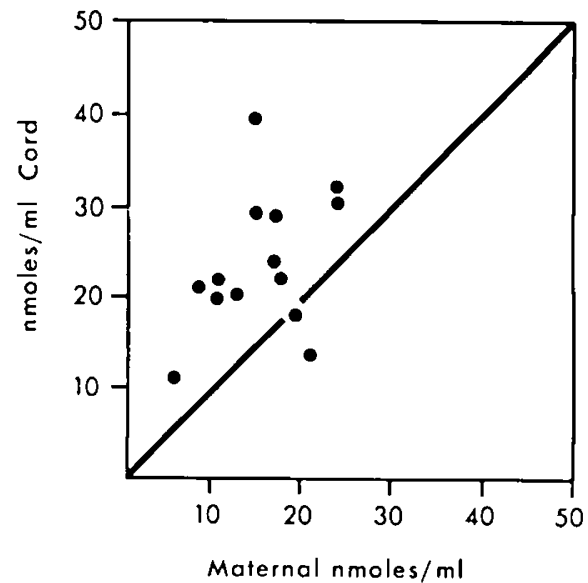

Fig. 4. Relationship between l-carnitine levels in cord blood and matcrnal venous blood.

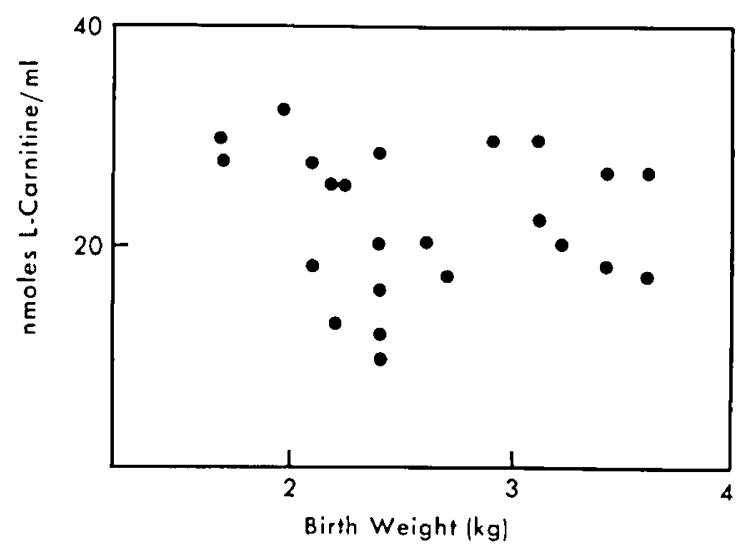

Fig. 5. Blood levels of L-carnitine in newborns of different body weight.

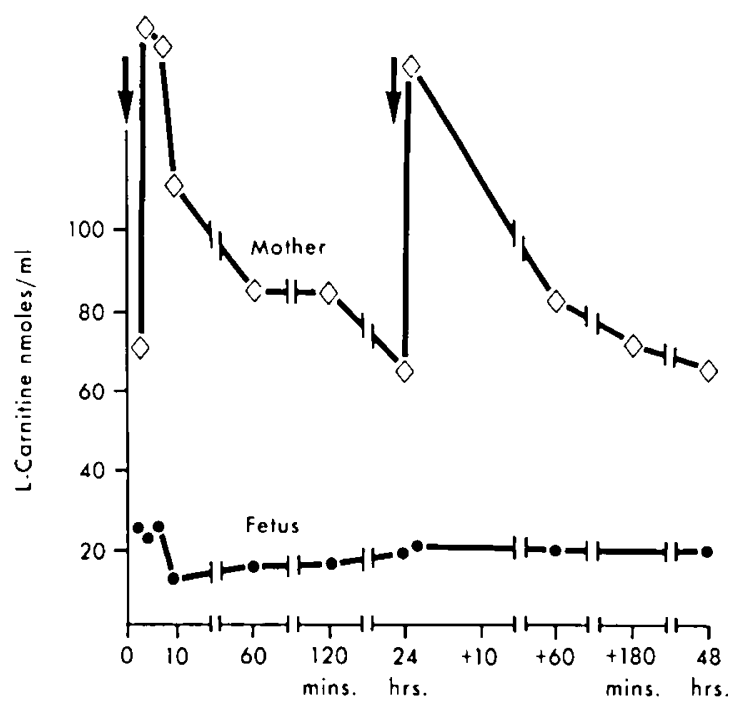

Fig. 6. Blood levels of 1 -carnitine in a pregname ewe $(\diamond-\diamond)$ and her fetus (1.30th day of pregnancy $(-\bullet)$ ). The black arrows indicate intra-arterial injection of L-carnitine into the ewe. Note lack of change in fetal levels and also 3 times higher levels in ewe.

make its own carnitine is not known for any species. In rats (7), and evidently, also in sheep, blood levels of carnitine in the fetus are low, lower than in the mother animal. In addition, there secms to be only a very slow exchange of carnitine between mother and fetus in both species. In man, on the other hand. 
fetal blood levels are significantly higher than maternal ones, a situation also found for most amino acids (13). These differences between mother and fetus and between species may be related to placental function. In the rat, radioactive carnitine injected into the mother rapidly accumulates in the placenta (10) but reaches the fetus only slowly.

Even though it is doubtful whether there is a direct correlation between the rate of fatty acid utilization and the blood level of carnitine, it is nevertheless tempting to suggest that the higher levels in human fetuses are related to their relatively greater capacity to oxidize fatty acids (10). However, increased fatty acid utilization is also a feature of pregnancy. Yet, blood levels of carnitine in pregnant women are significantly lower than in nonpregnant ones.

There is a gradual fall in the free carnitine content of amniotic fluid as gestation proceeds. The origin of this carnitine is not clear. Assuming that carnitine in $A F$ is of renal origin, it is possible that more carnitine is retained by the fetus as it approaches term and less is excreted. The lower level in the amniotic fluid of IDN may be related to the larger volume of amniotic fluid.

\section{CONCLUSION}

A highly significant negative correlation was found between amniotic fluid levels of free L-carnitine and gestational age in both normal fetuses and infants of diabetic mothers. However. at any age, levels were lower in IDM. Maternal blood levels (17 $\pm 3 \mathrm{nmol} / \mathrm{ml}$ ) were lower than levels in nonpregnant women and in cord blood. Usually, arterial umbilical blood also showed higher values than venous umbilical blood. In a pregnant ewe. L-carnitine blood levels were more than twice as high than in her 130-day-old fetus. Injection of L-carnitine into the carotid artery of the ewe did not result in any changes in carnitine levels in fetal blood.

\section{REFERLNCES ANI NOTES}

1. Augenfeld, J., and Fritz, 1. B.: Carnitine palmitoryltransferase activity and fatty acid oxidation by livers from fetal and neonatal rats. Can. J. Biochem., 48: $288(1970)$.

2. Cederblad, G., and Lindstedt, S.: A method for the determination of carnitine in the picomole range. Clin. Chim. Actit, 37: 235 (1972).

3. Cox, R. A., and Hoppel. C. L.: Biosynthesis of carnitine and 4-N-trimethylaminobutyratte from 6-N-trimethylly sine. Biochem. J., 1.36: 1083 (1973).

4. Drahota, Z., Hahn, P., Kleinzeller, A., and Kostolanka, A.: Acetoacetate formation by liver slices from adult and infant rats. Biochem. J., 93: 61 $(1964)$.

5. Fritz, 1. B., and Yu, K. T. N.: Long chain carnitine acyl transferase and the role of acylacarnitine derivatives in the catalytic increase of long chain fatty acid oxidation. J. Lipid Res. 4: 279 (196.3).

6. Hahn, P., and Skala, J.: Carnitine transferases in human fetal tissue. Biol. Neonat., 22:9(1973).

7. Hahn, P., and Skilla, J.: Carnitine and brown adipose tissue metabolism in the rat during development. Biochem. J., 127: 107 (1972).

8. Hahn, P., and Novak, M.: Development of white and brown adipose tissue. J. I.jpid Res., 16: 79 (1975).

9. Hahn, P. Beatty, C., and Bocek, M.: Carnitine transferases in brown fat of newborn and developing primates. Biol. Neonate, 30: 30 (1976).

10. Hahn, P., Vavrouskova, E., Girasek, J., and Uher, V.: Acctoacetate formatien by livers from human fetuses aged $8-17$ weeks. Biol. Neonate, 7: 348 (1964).

11. Hahn, P., and Skala, J.: The role of carnitine in brown adjpose tissue of suckling rats. Comp. Physiol. Biochem., 5lB: 507 (1975).

12. Seccombe, D. W., Dodek, P., Frohlich, J., Hathn. P., Skalia, J. P., and Campbell. D. J.: Automated method for L-carnitine determination. Clin. Chem., 22: 1589 (1976)

13. Snyderman, S. E.: Protein and aminoacid metabolism. In: U. Stave: Physiology of the Perinattal Peried. pp. $4+1-456$ (Appleton-Century-Croft, New York, 1970)

14. Towell, M. E., and Salvador, H. S.: Compression of the umbilical cord: An experimental model in the fetal goat. In: P. G. Crosignani and G. Pardi: Fetal Evaluation during Pregnancy and Labor, pp. 143-156 (Academic Press, New York, 1971).

15. This research was supported by grants from the Vancouver foundation and National Institutes of Health (2ROI HD)(1946-(1)4) and at contract from Health and Welfare, Canada.

16. Requests for reprints should he addressed to: P. Hahn. M.D. Professor of Padiatrics and Obstetrics/Gynaecology (UBC), Centre for Developmental

17. Received for publicition October $21,1976$.

18. Accepted for publication January $14,1977$.
Bilirubin

creatine

creatinine

feedback control glucaric acid newborns nikethamide phenobarbital

\title{
Negative Feedback Control of Neonatal Serum Creatine and Increased Urinary Creatinine Excretion after Enzyme-inducing Drugs
}

\author{
EDMUND TALAFANT"(23) ANNA HOSKOVÁ, AND ANNA POJEROVÁ \\ Department of Medical Chemistry, First Pediatric Clinic, J. E. Purkyné University, and Neonatal Unit of the First \\ Municipal Hospital, Brno, Czechoslorakia
}

Summary

Creatinine, creatine, and glucaric acid were determined in 24 hr urine samples collected from three groups of newborns on the first, fourth, and seventh day of life. Simultaneously creatine, creatinine, and bilirubin were estimated in serum of cord blood and of venous blood on the fourth and seventh day. Urinary creatinine excretion increased from the low values on the first day to the fourth day levels. In the control infants there was no further increase on the seventh day, on average. In both groups treated with oral nikethamide in addition to simultaneous intramuscularly applied phenobarbital in one group, and to oral sodium phenobarbital solution in the other one, further increase from the fourth to the seventh day was observed so that on the seventh day the creatinine excretion was significantly higher in both treated groups when compared with the seventh day values 